\title{
24. An Occurrences of Wentzella subtimorica in Northern Tai.
}

\author{
By Masao Minato. \\ (Comm. by T. Kato, M.I.A., Feb. 12, 1944.)
}

The material dealt with in this paper was collected by Naito in the northernmost part of Tai some years ago and is now kept in the Geological Institute of the Imperial University of Tokyo. Professor Kobayashi of that Institute gave me an opportunity to make a study on it. He has read this paper in manuscript and gave me valuable suggestions; I wish to take this opportunity to express my most cordial thanks to him. I am also indebted to Mr. Yujiro Naito of the Manchurian Oil-Company, the collector, as well as to Prof. Takao Kato for the presentation of this paper at the Akademy.

At the summit of the pass between Ban Doi Hoato and Ban Ai, about $80 \mathrm{~km}$. NNE of M. Jien Hami (M. dh Phayabh), there are exposures of limestone. It is here that the corals and fusulinids were collected by Naito. Upon suggestion by Prof. Kobayashi, a study was made on the fusulinids by Toriyama. The fossil locality is shown in the map in Toriyama's paper'). His study shows that the fusulinidlimestone contains

Pseudoschwagerina turbida F. and G. Kahler,

Pseudoschwagerina taiensis Toriyama,

Fusulinella cfr. Chaoi Lee and

Pseudoschwagerina (?) sp.

and the age of this fusulinid horizon is most probably Lower Permian. More precisely, this fossil horizon is older than the Pawa limestone of $\mathrm{Tai}^{2)}$ but younger than the Kyuanktaung limestone of Burma ${ }^{3)}$

The coralline horizon which I studied appears a little younger than the fusulinid horizon at the same place, because it yields Wentzelella subtimorica Huang. Although it is difficult to say anything definite on the known distribution of this species, I think that the coralline horizon is most probably Middle Permian. In other words, it is approximately synchronous with, but heteropic from, the Pawa limestone which is rich in fusulinids.

For the Kyuanktang limestone in the Shan plateau, Bose (in Chibber) suggested Upper Carboniferous, but I think this age-determination must be reconsidered, because Lonsdaleia salinaria i. e. Wentzella timorica is contained in the fossil list given by Chibber. On the basis of this species, I contented that the Kyuanktang limestone comprises the horizon equivalent to the coralline limestone here described. That

1) R. Toriyama (1944). On Some Fusulinids from Northern Tai. Japan. Jour. Geol. Geogr. vol. 19.

2) A. Heim and H. Hirschi (1939). A Section of the Mountain Range of North Western Sidna. Ecolog. Geol. Helv. vol. 32.

3) H. I. Chibber (1934). The Geology of Burma. 
they are roughly in the same niveau in the Permian sequence as the Pawa limestone which in turn belongs to the Neoschwagerina-Yabeina zone extensively spread from the Japanese islands to South China, is my opinion.

\section{Wentzelella subtimorica Huang.}

1925. Lonsdaleia (Waagénophyllum) timorica, Ozawa, Palaeontological and Stratigraphical Studies on the Permo-Carbon. Limestone of Nagato, Pt. 2, Palaeontology. Jour. Coll. Soc. Imp. Univ. Tokyo, vol. 45, art 6, pl. 13, figs. 7-9.

1932. Wentzella subtimorica Huang. Permian Corals of Southern China, Palaeontologia Sinica, Ser. B: vol. 12, fasc. 2, p. 59, pl. 4, fig. 1.

Description:-Corallum compound, composed of prismatic corallites ; its size not very small, averaging $8 \mathrm{~mm}$. in diameter. Wall originally thin, but always slightly thickened by stereoplasmic deposits. Major septa number 18-19, alternating with the same number of minor ones;

Fig. 1.

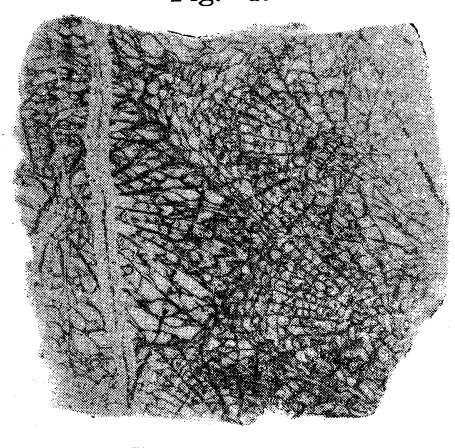

Fig. 2.

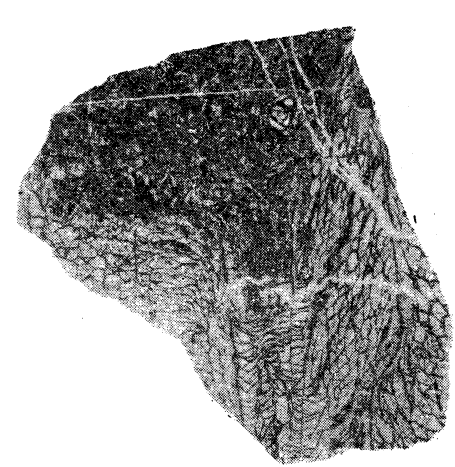

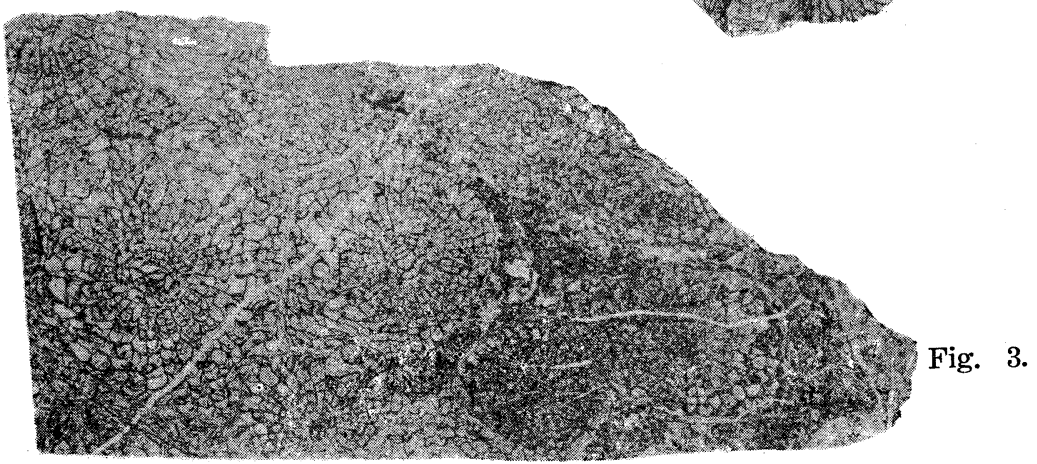

Figures 1-3. Wentzelella subtimorica Huang from North Tai $(\times 3)$.

all the septa thin, without any kind of deposits; minor septa reach almost the same length the major ones, though slightly thinner. All of the septa grow directly from the outer wall and there are no dissepimental area free from the septa. The distal ends of the major septa almost always reach the central area. Columella quite small, about the same as or a little less than one-fifth or sometimes onefourth of the diameter of the corallites; these collumella composed of somewhat irregularly arranged axial tabullae and a few septal lamellae; median plate indistict. 
In the longitudial sections, triaerial arrangement of corallites clearly observed. The central column can clearly be distinguished from the medial zone by the fact that the axial tabullae are more steeply inclined than the tabulae. The tabullae number 8 or 6 within a distance of $10 \mathrm{~mm}$. Numerous dissepimental vesciles point upwards and inwards near the outer wall and inwards on the inner side. The dissepiments are arranged subconcerntrically in the transverse section.

Remarks:--Because it is hardly possible to extract the coral from the mother rock, nothing can be mentioned of its external aspect. The description above presented is made on the basis of ten thin sections and several polished ones. From the size of columella and other characters shown in the sections, this species exactly coincides with Ozawa's $W$. timorica from Nagato as well as with Huang's $W$. subtimorica from South China.

$W$. subtimorica resembles $W$. timorica $\left(\right.$ Gerth) ${ }^{1)}$ closely but the former can be clearly distinguished from the latter in the tabulated area which is almost completely absent or poorly developed in Gerth's species.

With regard to the kinds of septa and the structures of the outer wall, Gerth ${ }^{2}$ recognized lately three specific groups in the genus Wentzelella, one of which comprises $W$. timorica, W. subtimorica, W. elegans and probably also $W$. flexuosa. His grouping of these four species in one section appear to me reasonable. Their specific distinction lie principally in the sizes of columeila and corallites. More precisely, in $W$. elegans ${ }^{3)}$ the columella is slightly larger than in W. subtimorica; in $W$. flexuosa $a^{4)}$ the corallites are much larger than in $W$. subtimorica.

1) H. Gerth: Anthozoen der Dyas von Timor. Paleontologie von Timor. Lief. IX, Taf. 145, figs. 1, 2.

2) H. Gerth: Permkorallen aus dem Nordwestlichen Himalaya. Palaeontogr. 88 A, p. 232.

3) T. K. Huang: Permian Corals of Southern China. Palaeontolo. Sinica. Ser. B. vol. 8 , fasc. 2, p. 61 .

4) Op. cit. p. 60 . 